\title{
Determinants of the Use of a Diabetes Risk-Screening Test
}

\author{
Nienke Nijhof - Claartje L. ter Hoeven • \\ Menno D. T. de Jong
}

Published online: 20 May 2008

(C) The Author(s) 2008

\begin{abstract}
A study was designed to investigate why people do or do not make use of a diabetes risk test developed to facilitate the timely diagnosis of diabetes. Data were collected using a web-based questionnaire, which was based on the Health Belief Model, the Theory of Planned Behavior, and the Threatening Medical Situations Inventory. People who had and had not used the risk test were recruited to complete the survey. The sample consisted of 205 respondents: $44 \%$ who had used the test and $56 \%$ who had not. The hypothesized relationships between the dependent variable (diabetes risk test use) and the determinants used in this study were tested using logistic regression analysis. Only two significant predictors of diabetes risk test use were found: gender and barriers. More women than men use the test. Furthermore, people who experience more barriers will be less inclined to use the test. The contribution of diabetes screening tests fully depends on people's willingness to use them. To optimize the usage of such test, it is especially important to address the barriers as perceived by the public. Two types of barriers must be addressed: practical barriers (time to take the test, fear of complexity of the test), and consequential barriers (fear of the disease and treatment, uncertainties about where to go in the case of an increased risk of diabetes).
\end{abstract}

\footnotetext{
N. Nijhof $(\bowtie)$

Department of Psychology \& Communication of Health \& Risk, Faculty of Behavioral Sciences, University of Twente, P.O. Box 217, 7500 AE Enschede, The Netherlands

e-mail: n.nijhof@focuscura.nl

C. L. ter Hoeven - M. D. T. de Jong

Department of Technical and Professional Communication,

Faculty of Behavioral Sciences, University of Twente,

P.O. Box 217, 7500 AE Enschede, The Netherlands
}

Keywords Diabetes risk test - Health belief model . Theory of planned behavior .

Threatening medical situations inventory

\section{Introduction}

'Diabetics in the workplace confront a tangle of laws' was the striking newspaper heading in the New York Times of December 26, 2006. The article states that the number of diabetics in the United States swelled by 80 percent in the past decade. Experts predict that diabetes is bound to become a conspicuous fact of life in the nation's labor force, raising many new issues for workers and managers [1]. Diabetes does not only raise various issues for workers and managers, but also for the health care system and the daily life of diabetes patients. Diabetes is a disease that must be treated timely to limit the chances of getting serious complications [2-4]. At least 171 million people worldwide (2.9\% of the world population) have diabetes, and this figure is expected to be more than doubled by 2030 to reach 366 million [5]. In the Netherlands, 600,000 people are diagnosed with diabetes and an estimated 250,000 people are undiagnosed diabetes patients, which together amounts to $5 \%$ of the Dutch population [6].

The Dutch Diabetes Foundation developed a diabetes risk-screening test in cooperation with the Free University Medical Centre, Wageningen University and the University Medical Centre Groningen to facilitate a timely diagnosis of diabetes. The Diabetes Risk Test, which can be found online or in a paper version at the local pharmacy, consists out of 11 short questions to measure the risk of having diabetes or getting it in the next 5 years. Despite the media attention for the test, relatively few people have used it so far. In this article, we will investigate why people do or do 
not fill out such a risk test. The results may be helpful to inform future strategies to promote screening tests for diabetes, which are the only effective way to reduce the harmful effects of this chronic disease [4].

To answer this question, a questionnaire based on the Health Belief Model (HBM) [7], the Theory of Planned Behavior (TPB) [8], and the Threatening Medical Situations Inventory (TMSI) [9] was developed. The HBM assumes that people will act rationally to avoid sickness and to promote their health. In earlier studies, the HBM appeared to be a good predictor for health-related behaviors $[10,11]$. The HBM was successfully used to investigate why women participate in breast cancer screenings [12], or why young insulin-dependent diabetes patients enroll in an educational program [13]. Several researchers state that the 'subjective norm' construct from the TPB would be a useful addition to the HBM $[14,15]$. The opinion of others appears to be a relevant factor in explaining many health-related behaviors. The 'subjective norm' was therefore incorporated as one of the explaining variables. Furthermore, the TMSI was used in this study. The TMSI measures cognitive confrontation (monitoring) and cognitive avoidance (blunting) in medical threatening situations. High monitor types are people who search for information, whereas low monitor people are the information avoiders. High blunter types are people who are easily distracted, while low blunter types are not. This typology could also contribute to the explanation of people's behavior with the Diabetes Risk Test. It is hypothesized that high monitors and low blunters will be more inclined to use risk tests, to fulfill their information needs see Fig. 1.

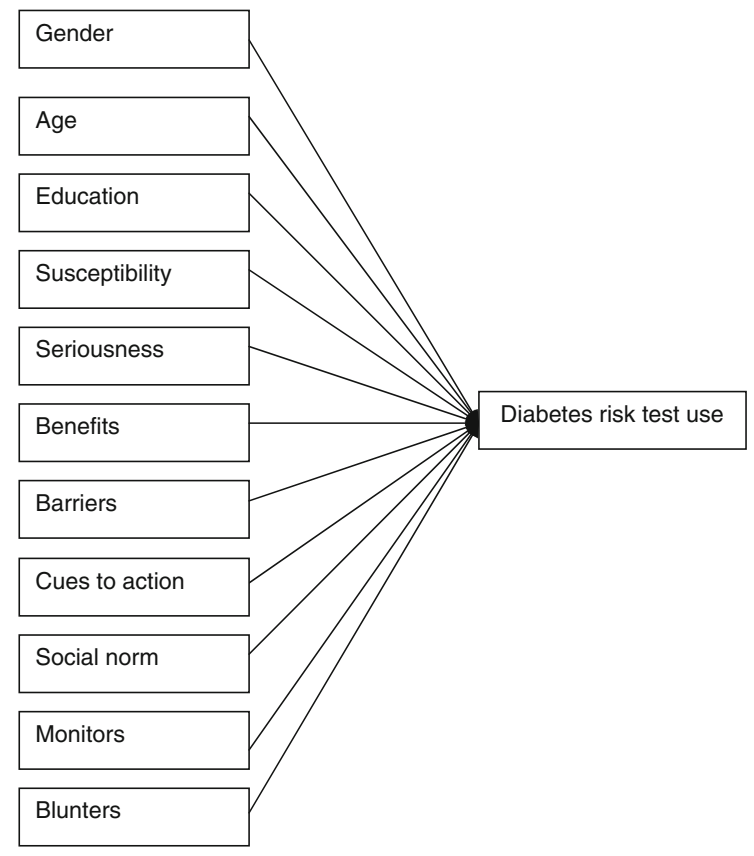

Fig. 1 Conceptual model with ten antecedents of diabetes risk test use

\section{Research Design and Methods}

\section{Data Collection}

The study consisted of a survey among people who had used the Diabetes Risk Test and people who had not. Data were collected from October to December 2006 using a web-based questionnaire. The Dutch Diabetes Foundation provided 300 e-mail addresses of patients and nonpatients who had used the Diabetes Risk Test. The group of respondents who had not used the risk test was collected using snowball sampling. Seventy people were emailed and asked to participate and to forward the participation request. Both groups were informed about the online questionnaire through e-mail with an explanation of the research, information about the Diabetes Risk Test, a time estimate (15 $\mathrm{min}$ ) and an endorsing statement from the Diabetes Foundation. This resulted in 205 respondents who completed the questionnaire: 90 people who had used the Risk Test (44\%) and 115 respondents who had not $(56 \%)$.

\section{Measures}

To answer the research question, a questionnaire was developed based on the HBM, TPB and the TMSI [8, 9, 16-18]. The questionnaire consisted of 71 items (in Dutch) with answer categories on five-point Likert scales, ranging from 1 (strongly disagree) to 5 (strongly agree).

The dependent variable, diabetes risk test use, was measured with a dichotomous yes/no question asking respondents whether they had filled out the risk test.

The demographic variables gender, age and educational level were also used as dichotomous variables. The respondents' age was split into two groups: younger than 45 vs. 45 and older, as the latter group is considered to be more of a risk group [6]. Educational level was dichotomized into high versus low.

The TMSI was incorporated in the questionnaire to measure monitoring and blunting. Four hypothetical threatening situations were described, followed by possible monitoring and blunting coping styles [9]. Perceived susceptibility was measured with seven items. A sample item was 'I'm often afraid something is wrong with my health.' Perceived seriousness was measured using six items. Sample items include 'Diabetes can seriously harm my well-being,' and 'Diabetes can be a hindrance for my daily life activities.' To measure the perceived benefits, six items were used. A sample item was, 'Diabetes can be treated better if it is diagnosed in time.' Barriers were measured using five items, for example 'It's too time-consuming to inform myself about the Diabetes Risk Test.' Cues to action were measured using five items focusing on signals 
in the environment that could activate thinking about diabetes. A sample item is 'The media pay a lot of attention to diabetes.' The TPB construct subjective norm was assessed with nine items. These items measured the attitude of the social environment towards the Diabetes Risk Test, assuming that the social environment influences behavior. A sample item is, 'My family would want me to do the Diabetes Risk Test.'

Aforementioned items were subjected to an exploratory factor analysis, and items that did not unambiguously load on a particular factor were excluded. Cronbach's alphas were computed to check the reliability of the constructs. This resulted in seven distinctive and sufficiently reliable constructs: the monitors ( $\alpha=0.83$; four items) and blunters ( $\alpha=0.77$; four items) typology, perceived susceptibility ( $\alpha=0.70$; three items), perceived seriousness $(\alpha=0.70$; four items), perceived benefits $(\alpha=0.74$; four items), barriers ( $\alpha=0.68$; five items), and subjective norm ( $\alpha=0.89$; three items). The items of 'cues to action' did not form one factor and were therefore excluded from further analysis.

\section{Results}

\section{Background Characteristics of the Respondents}

The response group $(N=205)$ represented $34 \%$ male and $65 \%$ female respondents. The respondents' age was between 18 and 89 years old, with a mean of 41 years (SD 16.6). Of all respondents, $7 \%$ were diabetics, which is somewhat more than in the general public (4\%). Compared to national statistics (2\%) [19], a fairly high percentage (18\%) of the respondents said not to know whether they were diabetes patients or not. The remaining $75 \%$ of the respondents said not to suffer from diabetes. Seventy-three percent of the respondents had heard of the existence of the Diabetes Risk Test. Of the respondents who were aware of the existence of the test, $60 \%$ had actually filled out the test.

\section{Determinants of Diabetes Risk Test Use}

The hypothesized relationships between the dependent variable (diabetes risk test use) and the determinants used in this study were tested using a logistic regression analysis. An important precondition for the explanatory power of the determinants is respondents' knowledge of the existence of the test. Therefore, respondents who had never heard of the Diabetes Risk Test were excluded from the analysis, which left an N of 149 (of whom $60 \%$ had filled out the test and $40 \%$ had not). A non-significant Hosmer and Lemeshow test showed that the model fitted the data $\left(\chi^{2}=13,90, d f=8, P<.08\right)$. As can be seen in Table 1 ,
Table 1 Logistic regression analysis: explanatory power of HBM factors, TPB and the TMSI (dependent variable = diabetes risk test use; yes $=1$, no $=0$ )

\begin{tabular}{lcc}
\hline Predictors & $\beta$ & Wald \\
\hline 1. Gender & 1.01 & $6.46^{*}$ \\
2. Age & -.61 & 2.34 \\
3. Education & -.57 & 2.23 \\
4. Susceptibility & .26 & 1.15 \\
5. Seriousness & .12 & .23 \\
6. Benefits & .23 & .79 \\
7. Barriers & -54 & $4.29 *$ \\
8. Social Norm & .17 & .69 \\
9. Monitors & -.06 & .05 \\
10. Blunters & -.34 & 2.12 \\
Nagelkerke $R^{2}$ & .21 & \\
Chi-square & 25.41 & \\
$d f$ & 10 & \\
\hline
\end{tabular}

$* P<.05$

the determinants explained $21 \%$ of the variance of diabetes risk test use (Nagelkerke $R^{2}=.21, P<.01$ ). Two significant predictors of diabetes risk test use were found: barriers to taking action, and gender. When people see barriers, they are less inclined to use the diabetes risk test. Besides, women are more likely to use the test then men.

\section{Conclusions}

The question why people do or do not fill out the Diabetes Risk Test is partly answered by more than one fourth of the respondents who did not even know of the existence of the risk test and therefore lacked the prerequisite knowledge to make this choice. As a result, one of the conclusions of this study is that it is important to generate sufficient media attention for diabetes risk-screening tests.

But also when people are aware of the test, they may still choose not to use it. Our analysis shows that it is particularly important to pay attention to the perceived barriers of using a diabetes risk-screening test. A closer look at the questions asked under the barriers construct showed that there are two types of barriers involved: (a) practical barriers (time-consuming nature of filling out the test, and the estimated difficulty of answering the questions in the test), and (b) consequential barriers (fear of the disease and its treatment, and uncertainty about where to go with a positive test result). A communication strategy for diabetes risk-screening tests should expressly address these concerns. Furthermore, it seems important to pay extra attention to men, who appear to be clearly less inclined to use the test than women. 
It seems remarkable that the personality traits monitors and blunters did not have any significant explanatory power in this study. However, in another study on people's information needs in preparation of medical intervention [20], monitor and blunter types did not explain the degree of this need for information either.

\section{Study Limitations}

The study reported in this article is a first attempt to investigate the determinants of diabetes risk test use. It is important to note that the study only focuses on one particular risk test in the Netherlands. More research is needed to verify the generalizability of our findings. Furthermore, the cross-sectional nature of the data calls for caution in inferring causal relationships from this study.

Unfortunately, several items had to be removed after the exploratory factor analysis. The construct 'cues to action' had to be removed entirely. This is unfortunate because this construct could have given more insight in the environmental signals that activate thinking about diabetes. Nevertheless, the overall internal validity of this study appeared to be strong. This makes the results reliable and therefore of practical use for developing communication strategies to promote diabetes risk test use.

\section{Implications for Diabetes Educators}

The results of this study underline the importance of a communicative strategy to promote diabetes risk-screening tests. The contribution of such tests to the early detection of diabetes entirely depends on the willingness of people to use them. As the percentage of people who had not heard of the test was strikingly high (27\%), it seems important to raise people's awareness of diabetes and the availability of a riskscreening test. Furthermore, the information campaign must specifically pay attention to the perceived barriers. It must be stressed to people that the test can be easily used and does not take a lot of time. It must also be emphasized that there are good medical facilities for people who end up with a positive test result, and, especially in the case of early diagnosis, good possibilities of limiting the disease's harmful effects.

Fear of the disease and its treatment are possibly hard to take away, but the communication strategy should clearly state that an early diagnosis is an effective way to reduce the harmful effects and need for additional treatment $[2$, 21]. This would imply an emphasis on the benefits of the test, another determinant of the HBM. The given information should inform people about the benefits of timely diagnosis because a timely treatment can help avoid severe and unnecessary complications.

Uncertainty about where to go in the case of a positive test result can be limited by communicating exactly what people can do when they find out that they have a high risk of having or getting diabetes. The test must not stand alone, but be embedded in a system of health care provision and after care, in which it is entirely clear who can help if the outcome of the test points towards diabetes and what is going to happen then.

Open Access This article is distributed under the terms of the Creative Commons Attribution Noncommercial License which permits any noncommercial use, distribution, and reproduction in any medium, provided the original author(s) and source are credited.

\section{References}

1. Kleinfield, N. R. (2006). Diabetics in the workplace confront a tangle of laws. The New York Times, December 26.

2. Wilkenson, H. L. C., Cohen, A. S., \& Kenadjian, B. G. (1995). Screening for diabetes. Journal of Chronic Diseases, 2, 464-476.

3. Koll, E., \& Hewitt, J. B. (2001). Adherence to 1997 diabetes screening guidelines in a large ambulatory clinic. The Diabetes Educator, 27, 387-392.

4. Sadler, G. R., Meyer, M. W., Marie Ko, C., Butcher, C., Lee, S., Neal, T., Reed, L., Veals, A. E., \& Gilpin, E. A. (2004). Black cosmetologists promote diabetes awareness and screening among African American women. The Diabetes Educator, 30, 676-685.

5. World Health Organization. (2007). Diabetes programme. Country and regional data. Available from: http://www.who.int/ diabetes/facts/world_figures/en. Accessed on October 19, 2007.

6. Diabetes Fonds. (2007). Over diabetes: Diabetes in cijfers. Available from: http://www.diabetesfonds.nl/overdiabetes. Accessed on October 19, 2007.

7. Rosenstock, I. M. (1966). Why people use health services. The Milbank Memorial Fund Quarterly, 44, 94-127.

8. Ajzen, I. (2007). Constructing a TpB questionnaire: Conceptual and methodological considerations [monograph on the Internet]. Available from: http://www.people.umass.edu/aizen/pdf/tpb. measurement.pdf. Accessed on October 19, 2007.

9. Van Zuuren, F. J., De Groot, I., Mulde, N. L., \& Muris, P. (1996). Coping with medical threat: An evaluation of the threatening medical situations inventory. Personality and Individual Differences, 21, 21-31.

10. Burnet, D., Plaut, A., Courtney, R., \& Chin, M. H. (2002). A practical model for preventing type 2 diabetes in minority youth. The Diabetes Educator, 28, 779-795.

11. Anderson, R. M., Funnell, M. M., \& Hernandez, C. A. (2005). Choosing and using theories in diabetes education research. The Diabetes Educator, 31, 513-520.

12. Hyman, R. B., \& Baker, S. (1992). Construction of the Hyman Baker mammography questionnaire, a measure of health belief model variables. Psychological Reports, 71, 1203-1215.

13. Bond, G. G., Aiken, L. S., \& Somerville, S. C. (1992). The health belief model and adolescents with insulin dependent diabetes mellitus. Health Psychology, 11, 190-198.

14. Schut, H. (1990). Gezondheidsvoorlichting bij Diabetes Mellitus. Een Medisch-Psychologisch Onderzoek naar Effecten van en Indicaties voor een Voorlichtingscursus. Dissertation University of Amsterdam.

15. Bish, A., Sutton, S., \& Golombok, S. (2000). Predicting uptake of a routine cervical smear test: A comparison of the health belief model and the theory of planned behaviour. Psychology \& Health, 15, 35-50.

16. Rosenstock, I. M., Stretcher, V. J., \& Becker, M. H. (1988). Social learning theory and the health belief model. Health Education Quarterly, 15, 175-183. 
17. Hyman, B., Baker, S., Ephraim, R., Moadel, A., \& Philip, J. (1994). Health belief model variables as predictors of screening mammography utilization. Journal of Behavioral Medicine, 17, 391-406.

18. Stein, J. A., Fox, S. A., Murata, P. J., \& Morisky, D. E. (1992). Mammography usage and the health belief model. Health Education Quarterly, 19, 447-462.

19. Rijksinstituut voor Volksgezondheid en Milieu. (2007). Diabetes mellitus. Omvang van het probleem. Available from: http://www. rivm.nl/vtv/object_document/o1259n17502.html. Accessed on October 19, 2007.

20. Eeckhaut, K., Van Zuuren, F. J., Grypdonck, M. H. F., Defloor, T., \& Van Vliet, M. J. (2002). Monitoring en blunting in verpleegkundig onderzoek: Een secundaire analyse op gegevens van de Nederlandstalige Threatening Medical Situations Inventory (TMSI). Gedrag Gezondheid, 5, 86-98.

21. Greenberg, R. A., \& Sacks, D. B. (2002). Screening for diabetes: Is it warranted? Clinica Chimica Acta, 315(1-2), 61-69. 